\title{
STUDIES OF THE ROLE OF THE LIVER IN HUMAN CARBOHYDRATE METABO- LISM BY THE VENOUS CATHETER TECHNIC. I. NORMAL SUBJECTS UNDER FASTING CONDITIONS AND FOLLOWING THE INJECTION OF GLUCOSE ${ }^{1}$
}

\author{
By PHILIP K. BONDY,2 DAVID F. JAMES, AND BETTY W. FARRAR
}

\author{
(From the Department of Medicine, Emory University School of Medicine, and the Medical \\ Service, Grady Hospital, Atlanta, Georgia)
}

(Received for publication September 3, 1948)

Previous observations on the role of the liver in carbohydrate metabolism have been made entirely in animals. Recently a method has been developed for obtaining specimens of hepatic venous blood and estimating the hepatic blood flow in human beings (1). This has supplied a tool which makes possible direct investigation of the activity of the liver during various phases of carbohydrate metabolism in man. The present paper deals with the application of this technic to the study of the response of the liver to the fasting state and to the intravenous injection of glucose solution.

\section{METHODS}

Hepatic blood flow was estimated by the bromsulfalein method of Bradley (1) in some cases and in others by the urea method of Myers (2). In the few cases where blood flow determinations were not done, it was assumed that the hepatic blood flow was equal to the mean found in our other patients.

The hepatic vein was catheterized by a radiopaque catheter inserted through the right antecubital vein and guided under fluoroscopic observation. The tip was placed centrally in the right lobe in such a position that a free flow of blood could be obtained on aspiration. Occasional checks of position were made during the course of the procedure and at the end of the test period. Bradley (1) has shown that the bromsulfalein extraction may vary from place to place in the same liver. This results in some variation in the estimated hepatic blood flow. In the present study, where serial observations were compared, this type of variation was minimized by keeping the catheter tip in the same location throughout the procedure. At least $5 \mathrm{ml}$. of blood were withdrawn from the catheter and discarded before samples were withdrawn in order to avoid the possibility of dilution of the sample by saline remaining in the catheter. Peripheral venous and arterial samples were obtained

\footnotetext{
1 Presented to the Southern Society for Clinical Research, New Orleans, La., January 27, 1948.

2 Present address : Department of Physiological Chemistry, Yale University School of Medicine, New Haven, Connecticut.
}

through indwelling Cournand needles usually placed in the left antecubital vein and the left femoral artery.

Glucose $(0.5 \mathrm{gm} . / \mathrm{kg}$.) was administered intravenously in $250 \mathrm{ml}$. of distilled water over a period of 15 minutes.

Blood samples were obtained simultaneously from the artery and hepatic vein before injection and 15, 45, and 60 minutes after the beginning of the infusion. The samples were taken into a sodium fluoride-oxalate mixture and were promptly treated to obtain the necessary filtrates. Glucose determinations were performed by the method of Nelson (3) using a 1:10 zinc hydroxide filtrate. In our laboratory this method has had a standard error of $\pm 1.0 \mathrm{mg} . / 100 \mathrm{ml}$. at a level of $100 \mathrm{mg}$./ $100 \mathrm{ml}$. Blood urea was determined on a $10 \%$ tungstic acid blood filtrate by the xanthydrol precipitation technic of Engel and Engel (5) and also on a 1:200 dilution of urine. With this method, the standard error of the urea determination was $0.1 \mathrm{mg} . / 100 \mathrm{ml}$. at a level of $20 \mathrm{mg}$./ $100 \mathrm{ml}$. All determinations were read on a Lumetron photoelectric colorimeter.

\section{CLINICAL MATERIAL}

The subjects of these experiments were 15 essentially normal volunteers who were convalescing from acute diseases. All were well nourished and had been on a diet supplying more than $200 \mathrm{gm}$. of carbohydrate for at least three days prior to the procedure. The subjects were fasted for 18 hours before the tests. In some cases 0.1 or $0.2 \mathrm{gm}$. of nembutal in $50 \mathrm{ml}$. of water was given orally about 30 minutes before the procedure. Every attempt was made to keep the subjects comfortable. Venipunctures and arterial punctures were done under procaine local anesthesia. The patients were usually at ease, and most of them dozed during the course of the experiment. As a result of the precautions taken, it seems unlikely that the normal physiological reactions to pain, fear, or anger significantly affected the observations.

\section{CALCULATIONS}

The arterio-hepatic venous difference (A-HV) in $\mathrm{mg} . / 100 \mathrm{ml}$. is obtained by subtracting the hepatic venous from the arterial concentration. When the concentration is higher in the hepatic venous blood than in the arterial, the result is a negative quantity, indicating that the liver was losing the substance into the circulation. Where the A-HV value is positive, the liver was retaining the sub- 
stance, either by storing it (e.g., glucose as glycogen) or by metabolizing it.

The hepatic venous system drains not only the liver but also the gastrointestinal tract and the spleen. Strictly speaking, therefore, the value for $\mathrm{A}-\mathrm{HV}$ represents splanchnic rather than hepatic metabolism. This is discussed below.

An attempt has been made to estimate the amount of glucose formed from protein in the liver, on the basis of the amount of urea released. Using Shaffer's (6) data for the $\mathrm{G} / \mathrm{N}$ ratios in diabetic dogs, it was assumed that the release of $1 \mathrm{gm}$. of nitrogen as urea represented the deamination of a sufficient quantity of amino acids to supply $3 \mathrm{gm}$. of glucose. On this basis $1 \mathrm{gm}$. of urea is equivalent to $1.4 \mathrm{gm}$. of glucose. The validity of this calculation is discussed below.

The total splanchnic metabolism is obtained by multiplying the value of $\mathrm{A}-\mathrm{HV}$ by the estimated hepatic blood flow, expressed as hundreds of milliliters per minute. Myers has shown (7) in man that the injection of glucose solution intravenously at a rate comparable to that used in these observations produces a mean decrease of hepatic blood flow of $10 \pm 3 \%$ during the first hour after the infusion. This minor alteration of hepatic blood flow has been disregarded in our calculations.

\section{RESULTS}

Hepatic blood flow: Estimations of the hepatic blood flow fell well within the range of normal as determined by Bradley (1) and by Myers (2) who found mean hepatic blood flows of $865 \pm 24$ and $800 \pm 71 \mathrm{ml} . / \mathrm{min} . / \mathrm{M}^{2}$, as compared with $851 \pm 71 \mathrm{ml} . / \mathrm{min} . / \mathrm{M}^{2}$ in this series (Table I).

Fasting hepatic glucose production: The splanchnic circulation contributed a mean of $3.5 \pm 0.7$ mg. of glucose per kilogram per minute to the circulation under fasting conditions (Table I).

Fasting hepatic urea production: The mean rate of urea production was found to be $0.21 \pm 0.5$ $\mathrm{mg} . / \mathrm{kg} . / \mathrm{min}$. This may be considered a reflection of the rate of deamination of amino acids and, therefore, it provides a rough estimate of the rate of gluconeogenesis. The urea excreted may be expressed as estimated equivalents of glucose formed. Under fasting conditions the glucose formed from protein represents $7.3 \pm$ $1.0 \%$ of the total hepatic glucose output (Table I). There was no relationship between the glucose output or the blood glucose concentration and the rate of urea production.

The effects of intravenous glucose: After the administration of $0.5 \mathrm{gm}$. of glucose per kilogram intravenously over a period of 15 minutes, a rise

TABLE I

Estimated hepatic glucose production, urea formation and blood flow under fasting conditions

\begin{tabular}{|c|c|c|c|c|c|c|c|c|c|}
\hline Subject & $\begin{array}{l}\text { Surface } \\
\text { area, M2 } \\
\text { Wt., kg. }\end{array}$ & $\begin{array}{l}\text { Hepatic } \\
\text { blood flow }\end{array}$ & $\begin{array}{l}\text { Glucose } \\
\text { output }\end{array}$ & $\begin{array}{l}\text { Urea } \\
\text { output }\end{array}$ & $\begin{array}{c}\text { Glucose } \\
\text { from } \\
\text { protein* }\end{array}$ & $\begin{array}{c}\text { Glucose } \\
\text { from } \\
\text { protein }\end{array}$ & $\begin{array}{l}\text { Glucose } \\
\text { calories }\end{array}$ & $\begin{array}{c}\text { Normal } \\
\text { BMRT }\end{array}$ & 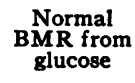 \\
\hline B. B. & $\begin{array}{c}1.49 \\
51.7\end{array}$ & $\begin{array}{c}\operatorname{ml} . / \min . / M^{2} \\
641 \ddagger\end{array}$ & $\begin{array}{c}\text { mg. } / \text { kg. } / \min . \\
2.4\end{array}$ & $\begin{array}{c}\text { mg./kg./min. } \\
.13\end{array}$ & .18 & $\begin{array}{l}\% \\
7.5\end{array}$ & $\begin{array}{c}\text { per } M^{2} / \min . \\
.268\end{array}$ & $\begin{array}{c}\text { cal. } / M^{2} / \min \\
.606\end{array}$ & $\begin{array}{r}\% \\
44\end{array}$ \\
\hline E. M. P. & & $711 \ddagger$ & 4.8 & .33 & .46 & 9.6 & .648 & .625 & 104 \\
\hline & & - & 1.6 & .09 & .13 & 8.1 & .200 & .650 & 31 \\
\hline M. B. & $\begin{array}{l}1.58 \\
55.0\end{array}$ & & 5.2 & .14 & .20 & 3.8 & .592 & .740 & 80 \\
\hline & $\begin{array}{l}1.89 \\
67.0\end{array}$ & 896 & 6.3 & .10 & .14 & 2.2 & .916 & .649 & 141 \\
\hline H. M. C. & $\begin{array}{l}1.72 \\
62.6\end{array}$ & 740 & 1.5 & .45 & .63 & 4.2 & .220 & .656 & 34 \\
\hline J. W. A. & $\begin{array}{l}1.73 \\
67.5\end{array}$ & 840 & 1.3 & .11 & .15 & 11.5 & .204 & .655 & 31 \\
\hline R. C. & $\begin{array}{l}1.94 \\
80.5\end{array}$ & 1210 & 1.9 & .12 & .17 & 9.0 & .320 & .641 & 50 \\
\hline W. M. & $\begin{array}{l}1.59 \\
50.2\end{array}$ & 920 & 6.1 & .44 & .62 & 10.1 & .760 & .650 & 117 \\
\hline Mean & & 851 & 3.5 & .21 & & 7.3 & .459 & & 70 \\
\hline $\begin{array}{l}\text { Standard } \\
\text { error }\end{array}$ & & 71 & 0.7 & .05 & & 1.0 & .094 & & 14.4 \\
\hline
\end{tabular}

* The method and rationale of converting urea excretion into equivalents of glucose produced from protein is discussed in the text.

t BMR estimated from the tables of Aub and Dubois.

$\ddagger$ Blood flow estimated by the urea method. 
TABLE II

Effect of the intravenous injection of glucose on the arterial and hepatic venous glucose levels (mg./100 ml.)

\begin{tabular}{|c|c|c|c|c|c|c|c|c|c|c|c|c|}
\hline \multirow{2}{*}{ Subject } & \multicolumn{3}{|c|}{ Fasting } & \multicolumn{3}{|c|}{15 Minutes } & \multicolumn{3}{|c|}{45 Minutes } & \multicolumn{3}{|c|}{60 Minutes } \\
\hline & $\mathbf{A}$ & HV & A-HV & A & HV & A-HV & $\mathbf{A}$ & HV & A-HV & $\mathbf{A}$ & HV & A-HV \\
\hline $\begin{array}{l}\text { L. L.* } \\
\text { J. C. B. } \\
\text { W. P. } \\
\text { A. P. } \\
\text { H. McK. } \\
\text { B. B. } \\
\text { E. M. P. } \\
\text { M. B. } \\
\text { L. W. } \\
\text { J. C. }\end{array}$ & $\begin{array}{r}86 \\
85 \\
74 \\
89 \\
75 \\
72 \\
108 \\
87 \\
84 \\
97\end{array}$ & $\begin{array}{r}111 \\
84 \\
83 \\
102 \\
90 \\
82 \\
130 \\
105 \\
109 \\
112\end{array}$ & $\begin{array}{l}-25 \\
+1 \\
-9 \\
-13 \\
-15 \\
-10 \\
-22 \\
-18 \\
-25 \\
-15\end{array}$ & $\begin{array}{l}445 \\
369 \\
304 \\
340 \\
343 \\
270 \\
331 \\
270 \\
262 \\
300\end{array}$ & $\begin{array}{l}394 \\
341 \\
271 \\
317 \\
328 \\
233 \\
298 \\
273 \\
264 \\
288\end{array}$ & $\begin{array}{l}+51 \\
+28 \\
+33 \\
+23 \\
+15 \\
+37 \\
+33 \\
-3 t \\
-2 \dagger \\
+12\end{array}$ & $\begin{array}{l}185 \\
153 \\
117 \\
182 \\
190 \\
181 \\
196 \\
170 \\
149 \\
234\end{array}$ & $\begin{array}{l}194 \\
166 \\
119 \\
176 \\
194 \\
194 \\
193 \\
161 \\
154 \\
201\end{array}$ & $\begin{array}{l}-11 \\
-13 \\
-2 \\
+6 \\
-4 \\
-13 \\
+3 \\
+9 \\
=5 \\
+33\end{array}$ & $\begin{array}{r}145 \\
74 \\
83 \\
144 \\
170 \\
137 \\
149 \\
133 \\
152 \\
172\end{array}$ & $\begin{array}{r}175 \\
166 \\
92 \\
139 \\
151 \\
137 \\
168 \\
121 \\
148 \\
187\end{array}$ & $\begin{array}{r}-30 \\
-92 \\
-9 \\
+5 \\
+19 \\
0 \\
-19 \\
+12 \\
+4 \\
-15\end{array}$ \\
\hline Mean & 86 & 100 & -14 & 310 & 290 & +20 & 175 & 173 & +2 & 135 & 145 & -11 \\
\hline Standard error & 3.9 & 5.4 & 2.6 & 12.7 & 11.4 & 5.0 & 11.0 & 8.8 & 3.4 & 11.5 & 9.3 & 10.3 \\
\hline
\end{tabular}

* This patient received $100 \mathrm{gm}$. of glucose, rather than the standard dose of $0.5 \mathrm{gm} . / \mathrm{kg}$. The data are therefore excluded from the statistical analysis.

$\dagger$ These samples were taken five minutes after termination of the glucose clysis.

in the arterial glucose level occurred. This gradually fell after the termination of the clysis until it reached normal levels. The shape of the arterial glucose tolerance curve indicated a normal carbohydrate metabolism in all cases (Table II).

The fasting hepatic venous glucose level was higher than the arterial in all cases except one (Table II, J. C. B.). There is no ready explanation for the inconsistency of this single observation.

Fifteen minutes after the clysis was begun, the hepatic venous glucose level was lower than the arterial in all but two cases (Table II, M. B. and L. W.). In these instances, technical difficulties caused a delay in obtaining the samples so that they were not collected until five minutes after termination of the clysis. At this time the arterial glucose level had begun to fall. It seems possible that an outpouring of glucose from the liver, stimulated by the sudden drop of arterial glucose concentration, might account for the negative values of $\mathrm{A}-\mathrm{HV}$ in these cases.

At 45 minutes after the beginning of the infusion, more than half of the patients had negative value for $A-V$, and the mean $A-H V$ was not significantly different from zero. At this time the mean arterial glucose level was $175 \mathrm{mg}$./ $100 \mathrm{ml}$. In some subjects, therefore, the liver began to give up glucose at a time when the arterial glucose level was still elevated. Such a response suggests that regulation of the splanchnic glucose balance may depend partly on the rate of fall of the glucose level in addition to the absolute glucose concentration in the blood.

At 60 minutes the tendency to release glucose from the liver into the peripheral circulation was more marked. At this time, however, the patients were reacting with less uniformity than during the periods immediately after the injection. This

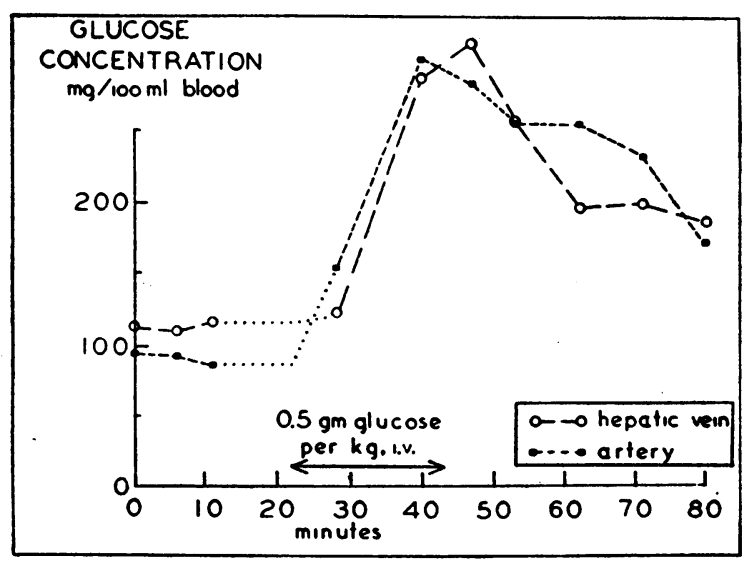

Fig. 1. Arterial and Hepatic Venous Glucose LeVels, Fasting and at Frequent Intervals after the Intravenous Injection of $0.5 \mathrm{GM}$. OF Glucose per Kilogram over a 15-Minute Period

Note the intermittent retention and release of glucose by the splanchnic system during the descending portion of the curve. 


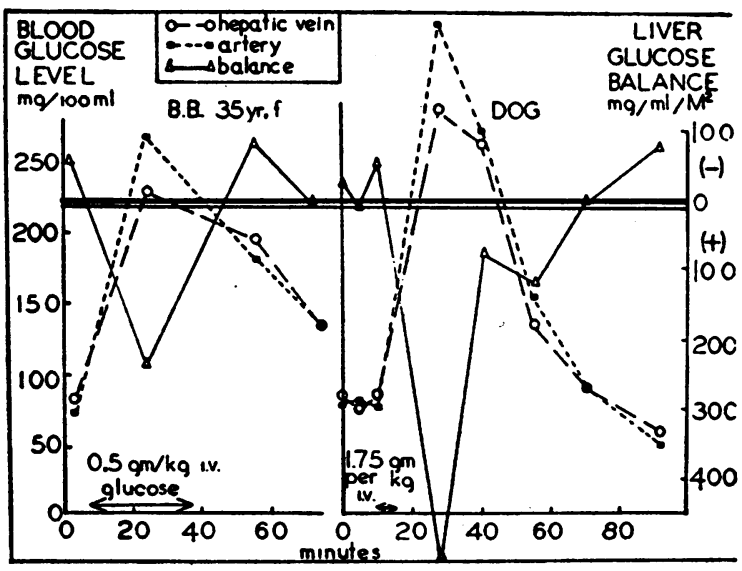

Fig. 2. Arterial and Hepatic Venous Glucose Levels and Estimated Hepatic Glucose Balance AFter the INTRAVENoUs INJECTION OF GLucose IN A Human Subject (Left) and a Dog (Right)

Balance values plotted above the zero line represent retention of glucose, and below the line represent release of glucose by the splanchnic system. The data for the $\operatorname{dog}$ are reproduced by permission of Dr. Soskin (8).

is reflected in the relatively large standard error for A-HV.

The observation that the splanchnic system could release glucose even in the face of high blood glucose concentrations suggested that the determining factor might be the rate of fall of the glucose level. To test this, one experiment was done in which samples were collected at frequent intervals. The curves obtained are shown in Figure 1. In this subject the hepatic venous concentrations fluctuated widely around the arterial curve. The significance of these data is discussed below.

The total glucose balance can be calculated by multiplying $\mathrm{A}-\mathrm{HV}$ by the hepatic blood flow. This has been done for patient B. B. and plotted, together with the arterial and hepatic venous curves, in Figure 2. For comparison an experiment of the same sort in a dog, reported by Soskin et al. (8), has been plotted in the same figure. In order to avoid superimposition of the curves, negative balances have been plotted above the double line and positive balances below. The greater excursion of the glucose curve in the dog is probably due to the fact that $1.75 \mathrm{gm}$. of glucose per kilogram were injected in five minutes, whereas in the patient $0.5 \mathrm{gm}$. per kilogram was injected in 15 minutes.
The peripheral venous glucose levels were invariably lower than the arterial and were usually lower than the hepatic venous levels under fasting conditions. After the infusion the venous level rose less sharply than did the arterial or hepatic venous concentrations. During the declining phase of the curve, the fall of the venous level was also less rapid. As a result, the concentration of glucose in the peripheral venous blood was usually higher than in the arterial or hepatic venous blood by the end of the observation period. These relationships are shown for a typical case in Figure 3.

\section{DISCUSSION}

The hepatic venous system drains not only the liver but also the gastrointestinal tract and the spleen. Strictly speaking, therefore, the value for A-HV represents splanchnic rather than hepatic metabolism. Unfortunately, there is no method available at present for obtaining portal blood in the intact human being. By keeping our subjects basal we have hoped to reduce the metabolism of the extra-hepatic tissues in the splanchnic system to a minimum, and thus achieve a close approximation of the activity of the liver itself. It is possible to estimate the magnitude and direction of the error introduced in the study of hepatic metabolism by our inability to obtain portal ve-

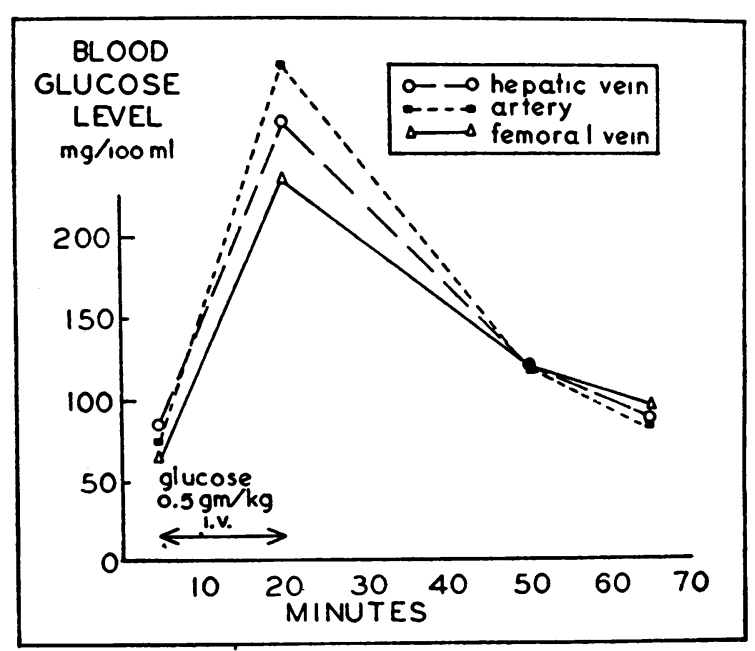

Fig. 3. Arterial, Peripheral Venous and Hepatic Venous Glucose Values Before and After the Administration of $0.5 \mathrm{Gm}$. of Glucose i.v. over a Period of 15 Minutes 
nous blood. Under fasting conditions in man, Sherlock and Walshe (9) and Ravault et al. (10) have shown that the portal glucose level is the same as that of the peripheral venous blood. London (11) found a consistently lower concentration of glucose in the portal vein of the dog than in the arterial blood. Since the portal blood contains less glucose than the arterial in the fasting subject, the amount of glucose released by the liver is actually greater than is indicated by the value of A-HV. The data of Soskin et al. (8) and of Lipscomb and Crandall (12) may be recalculated to determine the error introduced by using only the arterial and hepatic venous values. Under fasting conditions, the difference between the glucose production estimated from arterial and hepatic venous blood alone and that estimated from arterial, portal and hepatic venous blood, was less than the standard error of the glucose determinations in eight instances. There was a significant difference in two instances. In each case, where a difference occurred the value obtained from A-HV was lower than that from combined portal and arterial blood. After the intravenous administration of glucose to the dog of Soskin et al. (8), however, the error rose so that it was significant in every period, averaging $28.9 \%$ of the actual value. In every case, the value obtained by the use of $\mathrm{A}-\mathrm{HV}$ was lower than that obtained using both arterial and portal blood.

In the basal human subject, therefore, it seems probable that values obtained by the methods we have used are quite close to the true hepatic metabolism, although tending to be somewhat lower. After the injection of glucose, it is less accurate to speak of our results as indicating liver metabolism. Even in this case, however, the error is consistent and the major fluctuations introduced are due to the activities of the liver. With these reservations, therefore, we have used the terms "splanchnic" and "hepatic" interchangeably.

The data obtained from normal human subjects agree in all particulars with the observations made on experimental animals. The mean rate of glucose production in the fasting human being ( 3.5 $\pm 0.7 \mathrm{mg} . / \mathrm{kg} . / \mathrm{min}$.) falls within the range observed in dogs. Lipscomb and Crandall (12), studying dogs by a method comparable to the 'technic we have used, found a mean glucose production of $2.0 \pm 0.2 \mathrm{mg} . / \mathrm{kg} . / \mathrm{min}$. In their review of the literature they found reported values obtained by various methods, varying from 1.0 to $4.2 \mathrm{mg} . / \mathrm{kg} . / \mathrm{min}$. in the dog. Bouckaert and deDuve (13) have recently reported a value of $4.0 \pm .75 \mathrm{mg} . / \mathrm{kg} . / \mathrm{min}$. as the amount of glucose which must be infused to maintain the blood glucose level of a hepatectomized dog. They interpret this figure as equivalent to the amount of glucose released by the normal liver. It is of interest that the mean hepatic blood flow is less in man than in the dog $(23 \pm 1.5 \mathrm{ml} . / \mathrm{kg} . / \mathrm{min}$. for the human, versus $32 \pm 2.2 \mathrm{ml} . / \mathrm{kg} . / \mathrm{min}$. for the $\operatorname{dog}[12], p<0.01)$. The fact that the glucose output is equivalent suggests that a larger amount of glucose is released per milliliter of blood traversing the splanchnic circulation in man than in the dog.

Since the rate of release of glucose to the peripheral circulation may be considered as equivalent to the rate of utilization (combustion plus storage as glycogen or fat) of glucose in the peripheral tissues, our patients were utilizing glucose at a mean rate of $3.5 \mathrm{mg} . / \mathrm{kg} . / \mathrm{min}$. This is equivalent to $0.014 \mathrm{cal} . / \mathrm{kg} . / \mathrm{min}$. If calculated on the basis of calories per square meter of body surface, the mean rate of glucose release from the liver accounted for $.459 \pm .094 \mathrm{cal} . / \mathrm{M}^{2} / \mathrm{min}$. This represents a mean of $70 \pm 13.9 \%$ of the normal basal caloric requirement, calculated from the data of Dubois and Aub, for our patients. Since no direct measurement of the metabolic rate of the subjects was made, it is unwarranted to assume that the glucose output represented $70 \%$ of the actual metabolic requirement at the time of the observations. In three cases the rate of glucose production was higher than the total "normal" basal metabolic requirement (Table I), suggesting either that the subjects may not have been basal or that their basal metabolic rate may have been abnormal.

The conversion of urea production into equivalents of glucose production can only be a rough approximation of the true value. It has been estimated that the amount of glucose produced from protein might, under circumstances of maximal conversion, give rise to a $\mathrm{G} / \mathrm{N}$ ratio as high as 8.0 (4). In order to determine the maximum amount of glucose which could have been re- 
leased as a result of the observed rate of urea production, one would have to multiply the figures in Table I by a factor of 2.67. Even under these circumstances, however, the portion of glucose produced by the liver from protein breakdown would be only $19.7 \pm 2.7 \%$.

The finding of negative values for $\mathrm{A}-\mathrm{HV}$ at times when the arterial glucose value was still high is not in agreement with observations by Soskin et al. (8) in the dog. These observers found that the hepatic glucose balance did not become negative until the arterial glucose level had fallen to control levels. There are certain differences in the technics used which might account for the lack of agreement. The dogs utilized by Soskin were anesthetized and had been subjected to extensive surgical procedures, whereas the patients we were observing were in an essentially normal state. It is therefore possible that the animals observed by Soskin were not so sensitive to changes in the blood sugar level as were the human subjects. The fluctuations observed in A-HV can be explained by postulating that the hepatic glucose balance is sensitive both to the arterial glucose level and to the rate of fall of the glucose concentration. The influence of the rate of fall of the arterial glucose concentration may be partly mechanical, since a sudden fall of the intravascular concentration of dextrose would cause a diffusion of extracellular glucose back into the sinusoids, thus producing a negative value for $\mathrm{A}-\mathrm{HV}$.

It therefore seems probable that the rate of fall of the arterial glucose level plays a part in regulating the release of carbohydrate from the liver. This is well illustrated in the single case in which samples were obtained every ten minutes. Thus the liver, by intermittently releasing glucose to the circulation, brakes the descent of the blood glucose concentration and protects against the development of hypoglycemia.

It was noted that the peripheral venous glucose levels tended to be somewhat lower than those of the corresponding hepatic sample. This indicates that the peripheral tissues remove more glucose per milliliter of blood supplied to them than does the liver. No statement can be made regarding the relative total amounts of glucose involved, however, since no measurements of the blood flow through peripheral tissues were attempted. After the injection of large amounts of glucose, the rate of fall of the arterial glucose concentration was greater than that of the peripheral venous content, so that toward the end of the period of observation many patients had higher venous than arterial levels. This can probably be explained entirely on the basis of diffusion of glucose from the intercellular tissue spaces back into the peripheral venous system as the arterial glucose level fell below the concentration of the substance in the interstitial fluids.

\section{SUMMARY AND CONCLUSIONS}

The hepatic catheterization technic has been used in studying the role of the normal human liver in carbohydrate metabolism both in the basal state and after the administration of glucose intravenously. Under fasting conditions, the splanchnic system releases glucose to the circulation at a mean rate of $3.5 \pm 0.7 \mathrm{mg} . / \mathrm{kg} . / \mathrm{min}$. Of this, approximately $7 \%$ can be accounted for on the basis of gluconeogenesis from protein. The hepatic glucose production could account for a mean of $70 \%$ of the total normal basal metabolic requirement of the patients.

After the administration of glucose by vein, there is an immediate retention of glucose by the liver. Subsequently, as the arterial glucose level falls, glucose is released from the splanchnic circulation. The stimulus for this release appears to be both the arterial glucose level and the rate of fall of the glucose concentration. Evidence was obtained of the release of glucose from the liver at a mean arterial glucose level of 175 $\mathrm{mg} . / 100 \mathrm{ml}$.

It appears that the carbohydrate metabolism of the normal human being is similar to that of experimental animals on which previous studies have been made.

\section{BIBLIOGRAPHY}

1. Bradley, S. E., Ingelfinger, F. J., Bradley, G. P., and Curry, J. J., The estimation of hepatic blood flow in man. J. Clin. Invest., 1945, 24, 890.

2. Myers, J. D., The hepatic blood flow and splanchnic oxygen consumption of man; their estimation from urea production or bromsulfalein excretion during catheterization of the hepatic veins. J. Clin. Invest., 1947, 26, 1130. 
3. Nelson, N., A photometric adaptation of the Somogyi method for the determination of glucose. J. Biol. Chem., 1944, 153, 375.

4. Russell, J. A., Personal communication.

5. Engel, M. G., and Engel, F. L., The colorimetric microdetermination of urea nitrogen by the xanthydrol method. J. Biol. Chem., 1947, 167, 535.

6. Shaffer, P. H., Antiketogenesis. IV. The ketogenicantiketogenic balance in man and its significance in diabetes. J. Biol. Chem., 1922, 54, 399.

7. Myers, J. D., Personal communication.

8. Soskin, S., Essex, H. E., Herrick, J. F., and Mann, F. C., The mechanism of regulation of the blood sugar by the liver. Am. J. Physiol., 1938, 124, 558.

9. Sherlock, S., and Walshe, V., The use of a portal anastomotic vein for absorption studies in man. Clin. Sc., 1946, 6, 113.

10. Ravault, P., Girard, M., Viallier, J., and Bourdillon, M., Sur les valeurs chimiques comparées du sang de la circulation veineuse génerale et du sang porte chez l'homme. Compt. rend. Soc. de Biol., 1941, 135, 1233.

11. London, E. S., Angiostomie und Organestoffwechsel. Verlag des All-Union-Instituts für Experimentelle Medizin, Moskau, 1935.

12. Lipscomb, A., and Crandall, L. A., Hepatic blood flow and glucose output in normal unanesthetized dogs. Am. J. Physiol., 1947, 148, 302.

13. Bouckaert, J. P., and deDuve, C. H. R., The action of insulin. Physiol. Rev., 1947, 27, 39. 